\title{
The Influence of Topographical Factor Calculation on the Estimation of Water Erosion Intensity Using Geographical Information Systems
}

\author{
Natalia Junakova ${ }^{\mathrm{a}}$, Zuzana Klescova ${ }^{\mathrm{a}}$, Marcela Gergelova ${ }^{\mathrm{b}}$, Marian Holub ${ }^{\mathrm{a}}$ \\ ${ }^{a}$ Faculty of Civil Engineering, Technical University of Kosice, Institute of Environmental Engineering, Vysokoskolska 4, Kosice 042 00, Slovakia \\ ${ }^{b}$ Faculty of Mining, Ecology, Process Control and Geotechnology, Technical University Kosice, Institute of Geodesy, \\ Cartography and Geographical Information Systems, Park Komenskeho 19, Kosice 043 84, Slovakia
}

\begin{abstract}
During the recent years, there has been a surge of concern and attention in Europe to soil degradation processes that deteriorates soil quality by partially or entirely damaging one or more of its functions. Degradation processes occurring in Europe are widely studied and incorporated to soil protection policies on national and European levels.

One of the most widespread forms of soil degradation in Europe is soil erosion by water which affecting an estimated 105 million ha, or $16 \%$ of Europe's total land area (excluding the Russian Federation).

The soil erosion modeling may be useful in the design of the erosion-control measures and the evaluation of land-use management practices. Over time, different empirical models have being developed however, the Universal Soil Loss Equation (USLE) given by Wischmeier and Smith is extensively used for prioritization of the watersheds. Significant role in generation, quantification and management of the soil erosion model parameters have geographical information systems (GIS). The importance of the GIS techniques integration to quantify the surface erosion risk is determined by the speed of the performing operations, the accuracy of the results and the possibility of their spatial representation.

The paper is focused on the determination and evaluation of water erosion intensity in the basin of river Tisovec in Slovakia. Water erosion is modeled using the universal soil loss equation through geographic information systems. There are used two methods for calculating the topographic factor (LS factor). The first variant of the LS factor calculation is methodology according to the USLE using the manual method with choice of characteristic drainage profiles. The second option is to determine the LS factor by Mitasova methodology.

Modeling of water erosion intensity using geographic information systems can establish in which parts of the land limit values of soil loss are exceeded and thereby change crop rotation or design and implement the erosion control practices.
\end{abstract}

Keywords: water erosion; modelling; Universal Soil Loss Equation (USLE); geographical information systems (GIS).

\section{Introduction}

Soil erosion is a serious type of soil and land degradation in many parts of the world. According to the GLASOD assessment - Global assessment of soil degradation, in Europe, in the 1990s, excluding the Russian Federation, about 114 million ha or more than $17 \%$ of the total land area were affected by soil erosion, of which more than 24 million ha or approximately $4 \%$ show high or extreme degradation and nearly 70 million ha or $11 \%$ were affected by moderate degradation. Major type of degradation was erosion by water (about 16\% of Europe's total land area), while erosion by wind interested only $1.5 \%$ of the territory [1]. A recent new model of soil erosion by water constructed by Joint Research Centre - JRC has estimated the surface area affected in the EU-27 at 1.3 million $\mathrm{km}^{2}$. Almost $20 \%$ is subjected to soil loss in excess of $10 \mathrm{t} / \mathrm{ha} /$ year [2]. In Slovakia about 55\% of agricultural land is affected by varying intensities of water erosion [3].

Increasing the awareness amongst scientists and policy makers about the problem of soil degradation through erosion in Europe is now an urgent requirement. The identification of areas that are vulnerable to soil erosion can be helpful for improving our knowledge about the extent of the areas affected and, ultimately, for developing measures to keep the problem under control.

Corresponding author: Natalia Junakova. E-mail address: natalia.junakova@tuke.sk

http://dx.doi.org/10.3846/enviro.2014.030

(C) 2014 The Authors. Published by VGTU Press. This is an open-access article distributed under the terms of the Creative Commons Attribution License, which permits unrestricted use, distribution, and reproduction in any medium, provided the original author and source are credited. 
One important form of erosion assessment is from direct measurements or field observations of erosion features, however using conventional methods is expensive and time consuming yet. An alternative to the direct measurements and actual erosion estimates would be the use of models to estimate the risk of erosion. A wide variety of models are available for assessing soil erosion risk. The most widely applied empirical model in Europe - USLE (Universal Soil Loss Equation) is composed of six factors to predict the long-term average annual erosion loss from sheet flow in tons per unit area [4]. The main limitation of this model is that it is effective for erosion through sheet flow only on short slopes $(<300 \mathrm{~m})$ and not for concentrated flow or long slopes. Therefore, computing of length slope gradient factor (LS factor) is most problematic part of this equation. This drawback can be repressed by modification of LS factor according to Mitasova [5-6], where the influence of profile convexity/concavity using segmentation of irregular slopes is incorporated.

Various modifications of the USLE equation are often applied to estimate of soil loss using GIS software that maps soil erosion, easily identify areas that are at potential risk of extensive soil erosion and provide information on the estimated value of soil loss at various locations.

In this study, Geographic Information Systems (GIS) are used to predict and locate potential erosion areas in watershed in Eastern Slovakia using the universal soil loss equation. Contribution discusses about two methods for calculating the topographic factor LS. The first variant of the LS factor calculation is methodology according to the USLE equation by using the manual method with choice of characteristic drainage profiles. The second option is to determine the LS factor by Mitasova methodology.

\section{Material and methods}

\subsection{Study area}

Soil erosion intensity was assessed in the Tisovec stream catchment (Fig. 1), situated in Bardejov district, Eastern Slovakia. The average annual rainfall in this area is about $650-750 \mathrm{~mm}$, with maximum in summer months. The mean annual temperature is about $8.3{ }^{\circ} \mathrm{C}$ with a maximum of $20^{\circ} \mathrm{C}$ in the month of July and a minimum of $-3{ }^{\circ} \mathrm{C}$ in January. Soil types of the catchment are, in general, planosols, cambisols and albic luvisols. From the point of soil texture, medium heavy soils (sandy loam) occur in this area. According to the content of skeleton in the soil, slightly stony soils lead. Majority of land has slope more than $8 \%$. The land use of the catchment was found to be mixed type.

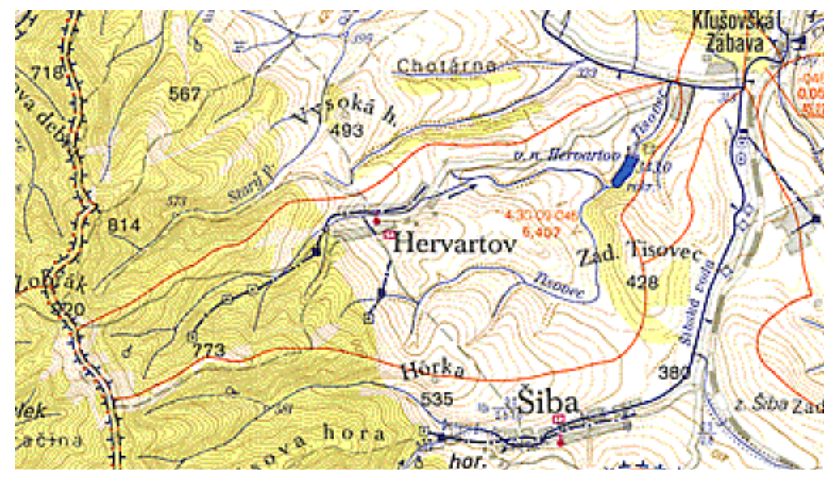

Fig. 1. Location of the Tisovec catchment

The upstream part and middle part of the Tisovec catchment is an area mainly covered with forest (39.2\%) and pastures $(21.7 \%)$, while the lower part is an arable land (21.4\%) mainly used for cereals (spring barley, winter wheat), corn silage and winter oilseed rape growing. The rest of the land area is for other uses.

In the narrowest part of the Tisovec stream, the Klusov small water reservoir is located in rugged terrain with slopes of different inclinations. It drains an area of $6.4 \mathrm{~km}^{2}$ and has a surface area of 2.2 ha when full. The reservoir's total capacity is $72,188 \mathrm{~m}^{3}$ and length is about $494 \mathrm{~m}$. It has a mean depth of $3.5 \mathrm{~m}$ and reaches a maximum water depth at the dam of $9.57 \mathrm{~m}$. The original use of reservoir was for retention of high water, irrigations and recreational purposes. At present it is utilized as fishery.

The rugged terrain, climatic conditions and predominant presence of the medium soils (sandy loam) classify this region between sensitive regions in terms of the water erosion presence.

\subsection{Methodology for assessment of soil erosion intensity in the catchment}

Several mathematical models were developed to estimate the soil loss by surface erosion. One of the widely known and used empirical soil erosion model is USLE, developed by Wischmeier \& Smith, which estimates soil loss on arable land as a result of climate, topography, soil properties, land cover and land management. The equation for calculating the mean annual rate of soil erosion is the following [4]:

$$
\mathrm{G}=\mathrm{R} \times \mathrm{K} \times \mathrm{L} \times \mathrm{S} \times \mathrm{C} \times \mathrm{P}
$$


where $\mathrm{G}$ represents the potential long term average annual soil loss in tons per hectare; $\mathrm{R}$ is the rainfall and runoff factor by geographic location in MJ.ha ${ }^{-1} \cdot \mathrm{cm} \cdot \mathrm{hr}^{-1}$; $\mathrm{K}$ is the soil erodibility factor in t.ha.hr.ha ${ }^{-1} \cdot \mathrm{MJ}^{-1} \cdot \mathrm{mm}^{-1}$; L,S is the length slope gradient factor; $\mathrm{C}$ is the crop/vegetation and management factor and $\mathrm{P}$ is the support practice factor.

Because of nonlinearity in several of the USLE terms and nonlinear distribution of factor values in the field, proper application of the USLE requires computing soil loss for individual profiles.

The effect of topography on soil erosion account slope length and slope steepness factors (LS factor). Values for slope length and steepness can be determined rapidly and easily by survey methods in small, field-sized areas with simple topography. But estimating LS values on a watershed basis is a problem because the field survey required to obtain the large number of profile measurements are time-consuming and costly, especially in large watersheds with complex topography. Slope length in the USLE is defined as "the distance from the point of origin of overland flow to the point where either the slope gradient decreases enough that deposition occurs or the runoff water enters a well-defined channel". Proper selection of slope length is difficult and depends on accurately indentifying a well-defined channel or the point where deposition begins [7]. The value of LS can be obtained from the equation [8]:

$$
\mathrm{LS}=\left(0.065+0.045 \mathrm{~S}+0.0065 \mathrm{~S}^{2}\right)^{*}(\mathrm{~L} / 22.1)^{0.5}
$$

where LS is the slope-length gradient factor, $\mathrm{S}$ is the slope steepness in percent and L is the length of slope in meters. Other versions of the above formula are available with minor alterations. However, this has been used as standard.

The topographic factor for USLE has been improved by incorporation of the influence of profile convexity/concavity using segmentation of irregular slopes and by improving the empirical equations for the computation of LS. A simpler, continuous form of the equation for computation of the LS factor at a point $r=(x, y)$ on a hillslope, is [5-6]:

$$
\operatorname{LS}(\mathrm{r})=(\mathrm{m}+1) \cdot\left(\mathrm{A}(\mathrm{r}) / \mathrm{a}_{0}\right)^{\mathrm{m}} \cdot\left(\operatorname{sinb}(\mathrm{r}) / \mathrm{b}_{0}\right)^{\mathrm{n}}
$$

where $\mathrm{A}[\mathrm{m}]$ is upslope contributing area per unit contour width, $\mathrm{b}[\mathrm{deg}]$ is the slope, $\mathrm{m}=0.2$ and $\mathrm{n}=1.2$ are parameters for a specific prevailing type of flow and soil conditions, and $a_{0}=22.1 \mathrm{~m}=72.6 \mathrm{ft}$ is the length and $\mathrm{b}_{0}=0.09=9 \%=5.16 \mathrm{deg}$ is the slope of the standard USLE plot [6].

Determination and evaluation of water erosion in the Tisovec stream catchment were realized using the implementation of the USLE equation in a raster GIS environment. Average annual soil loss in the catchment was estimated using two methods for calculating the topographical factor LS. The first variant of the LS factor calculation is methodology of using the manual method with choice of characteristic drainage profiles (2). The second option is determining of the LS factor by Mitasova methodology (3).

The database used for estimating the annual rate of surface erosion was consisting of the basic background map at scale 1:10,000; map of pedo-ecological units; the land use map and the rainfall erosivity index map in Slovakia. Individual GIS layers of USLE factors were obtained by converting of vector digital map data to raster, and all factors were multiplied together for calculating the final map of soil loss. In this study, ArcGIS software was used to create the relevant thematic layers for the application of the USLE. "Raster Calculator" tool of the "Spatial Analyst" extension was used to build the following expression (4):

$$
\mathrm{R} *[\mathrm{~K}] *[\mathrm{C}] *[\mathrm{P}] *[\mathrm{LS}]
$$

which, when applied to all polygons in a raster coverage of the Tisovec catchment, produced a map of soil loss in one year. Average soil losses calculated by these two methods were compared because of using different topographical factor calculations.

\section{Results and discussion}

The data layer for rainfall-runoff erosivity factor $(\mathrm{R})$ was generated from the county $\mathrm{R}$ factor data, determined for investigated area according to statistical values obtained from historical weather records derived by Malisek [9]. This value is a constant entered in the final equation, and a value $\mathrm{R}=22,43 \mathrm{MJ} \cdot \mathrm{ha}^{-1} \cdot \mathrm{cm} \cdot \mathrm{hr}^{-1}$ was used for region of Bardejov.

Source material needed to create a K factor layer was the map of pedo-ecological unit (BPEJ). These data were georeferenced and the polygons that represent vector data were drawn. Polygon attribute table was created by using third and fourth place of the relevant evaluated pedo-ecological unit code (BPEJ). Than vector data for K factor were converted to a raster dataset using function "Feature to raster".

The $\mathrm{C}$ factor GIS layer was created along with its corresponding attribute table. A relational join was performed to append the values to the land use theme using Table 1. This $\mathrm{C}$ factor GIS layer was then converted to a grid.

Table 1. Land use and $\mathrm{C}$ factor values on agricultural land in the catchment

\begin{tabular}{lll}
\hline Plot & crop & C factor \\
\hline $1004 / 1$ & potatoes & 0.6 \\
$2003 / 1$ & corn silage & 0.49 \\
$2001 / 1$ & winter wheat & 0.22 \\
$3101 / 1$ & spring barley & 0.11 \\
\hline
\end{tabular}


There are no effective erosion control measures in the Tisovec catchment and as a result the P factor was set at 1.0.

The first variant of the LS factor calculation is methodology of using the manual method with choice of characteristic drainage profiles. The input source for LS factor calculating was the plot map at a scale of 1:10,000, where polygons of individual plots were drawn and the values for slope length (length of drainage profiles) were determined. From the contour lines, values for slope steepness in the Tisovec catchment were determined and digital terrain model (DTM) was creating using "Topo to Raster" tool as an interpolation method. The "Slope" tool was used to create a slope raster for an area expressed in percentages. The LS factor was then computed using "Raster Calculator" tool of the "Spatial Analyst" extension according to (2).

The second variant computed the LS factor according to Mitasova methodology, where the influence of profile convexity/concavity using segmentation of irregular slopes is incorporated. The procedure for computation was as follows [10]:

- using the "Spatial Analyst" extension: slope was derived from DTM;

- using the "Hydrological" extension: sinks in the DTM were identified and filled;

- the filled DTM was used as input to determine the "Flow Direction";

- the "Flow Direction" was used as an input grid to derive the "Flow Accumulation".

The LS factor was then computed using "Raster Calculator" from the menu to build an expression for estimating LS, based on flow accumulation and slope steepness using equation (5), where resolution (pixel size of raster data) is $5 \mathrm{~m}$ :

$$
\mathrm{LS}=(\mathrm{m}+1) \cdot(\text { FlowAccumulation } \cdot \text { resolution } / 22.1)^{\mathrm{m}} \cdot(\sin (\operatorname{slope} \cdot 0.01745) / 0.09)^{\mathrm{n}}
$$

The USLE factor layers of K, C and LS are presented in Figures 2-5, respectively. Average soil losses calculated by using different topographical factor determination are shown in Figure 6.

As seen in Figure 4, the higher values of LS factor are observed on short slopes with simple topography. On the other hand, calculation of LS factor according to Mitasova showed the higher values of this factor in the thalweg, where long and concentrated flow is occurred (Fig. 5). The main limitation of the USLE is that it is effective for erosion through sheet flow only on short slopes $(<300 \mathrm{~m})$ and not for concentrated flow or long slopes. Therefore the change of the LS factor calculation can repress this drawback and also influences the resulting values of soil loss (Fig. 6).

As seen in Figure 6, the soil loss calculated by various methods is influenced by the way of determining the LS factor. When standard USLE factors are used for calculation, the higher soil loss is located on regular shape slopes with sheet surface flow (sheet erosion). In areas where not suitable crops are grown, soil losses exceed the limit values according to Slovak Act No. 220/2004 [11]. Variant LS factor according to Mitasova results in a change of maximum soil loss distribution. Using this calculation not only sheet erosion is observed but also rill erosion with concentrated flow in the thalweg occurs. Soil losses by rill erosion there, severalfold exceed limit values according to [11] and therefore it is necessary to prevent and control erosion using effective erosion controls.

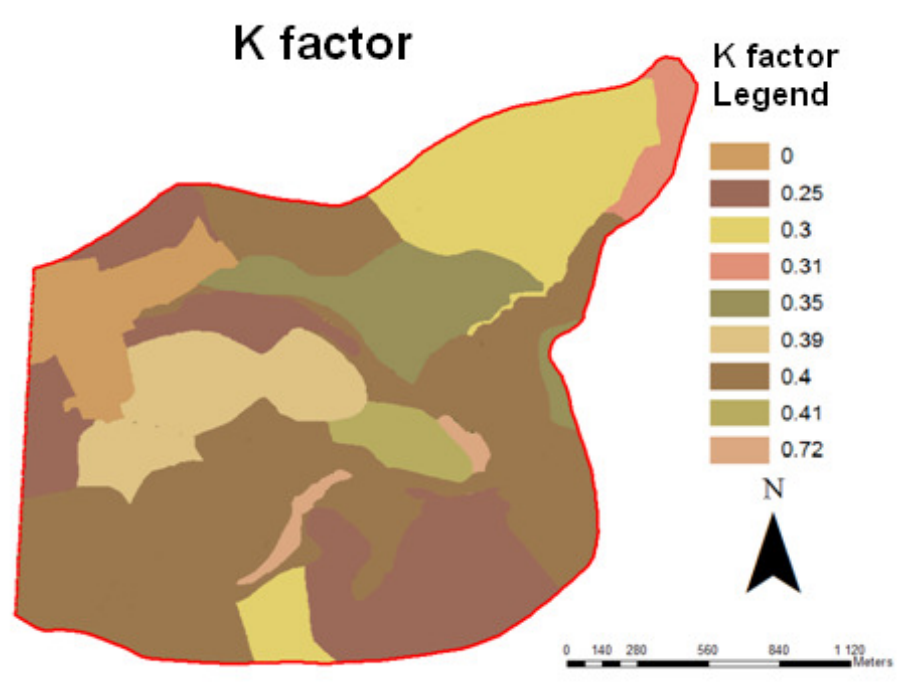

Fig. 2. K factor layer 


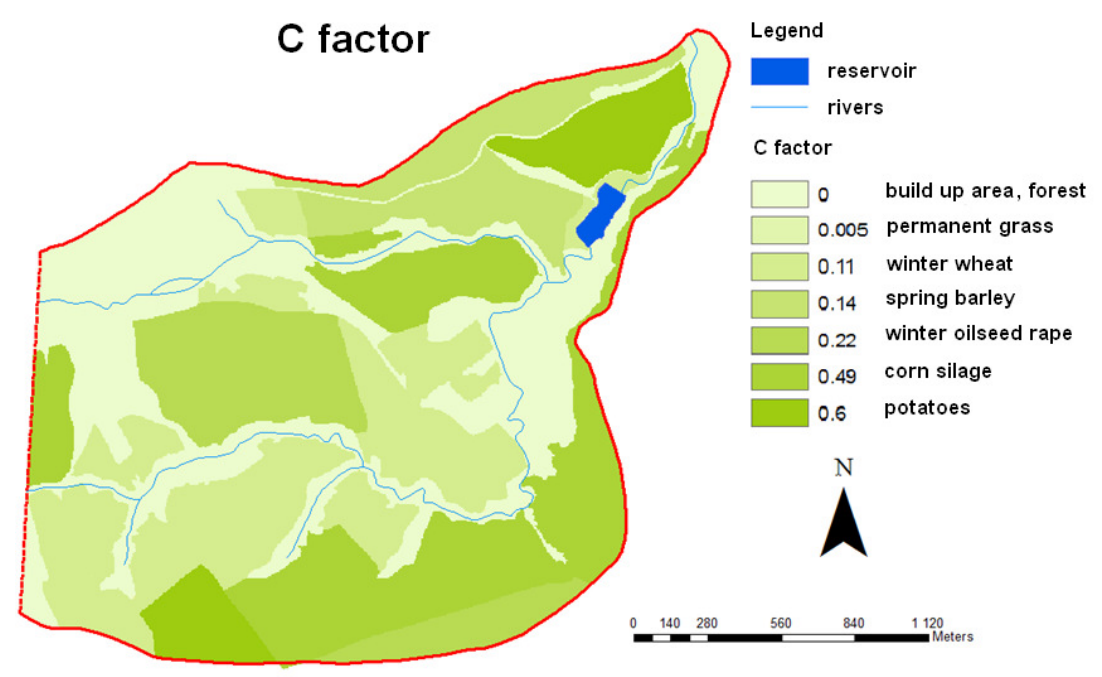

Fig. 3. C factor layer

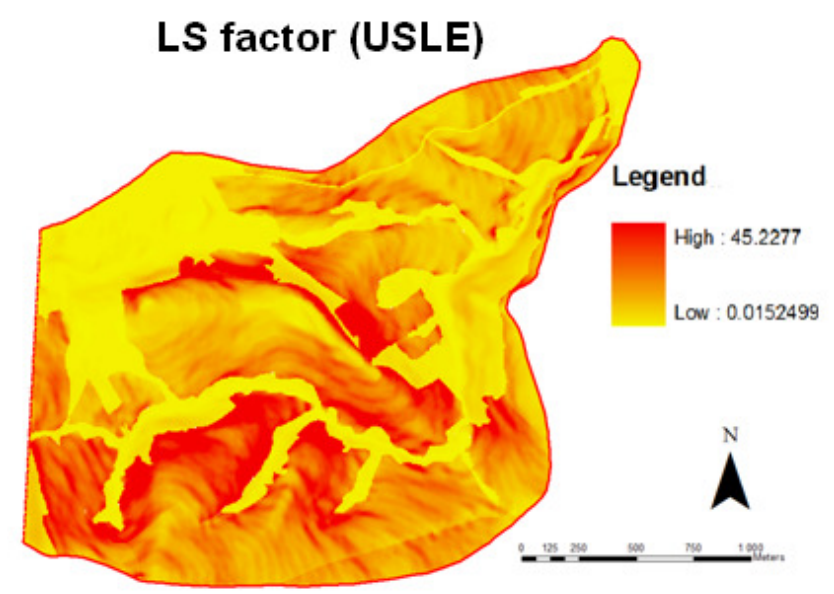

Fig. 4. LS factor layer using manual method with choice of characteristic drainage profiles

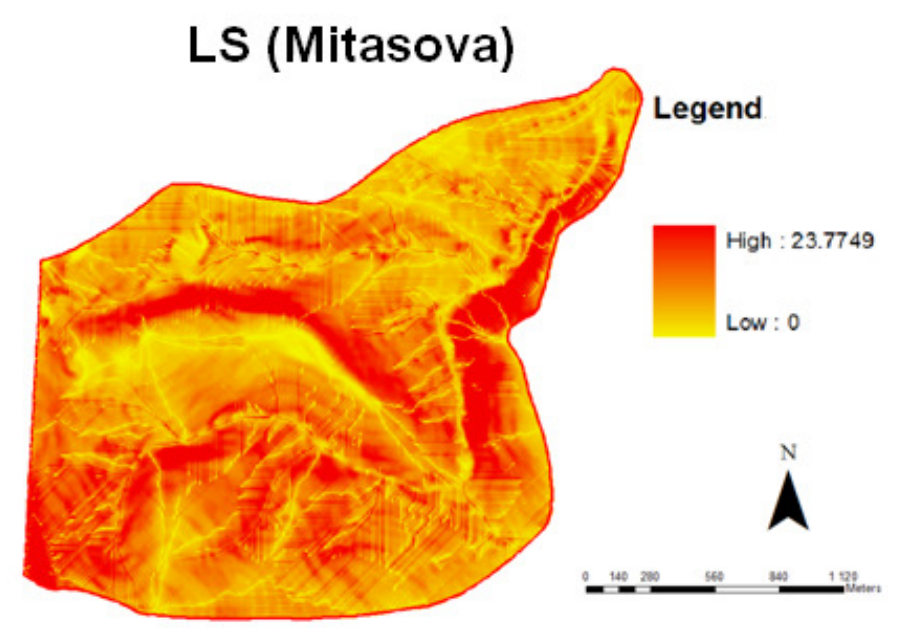

Fig. 5. LS factor layer using Mitasova method 

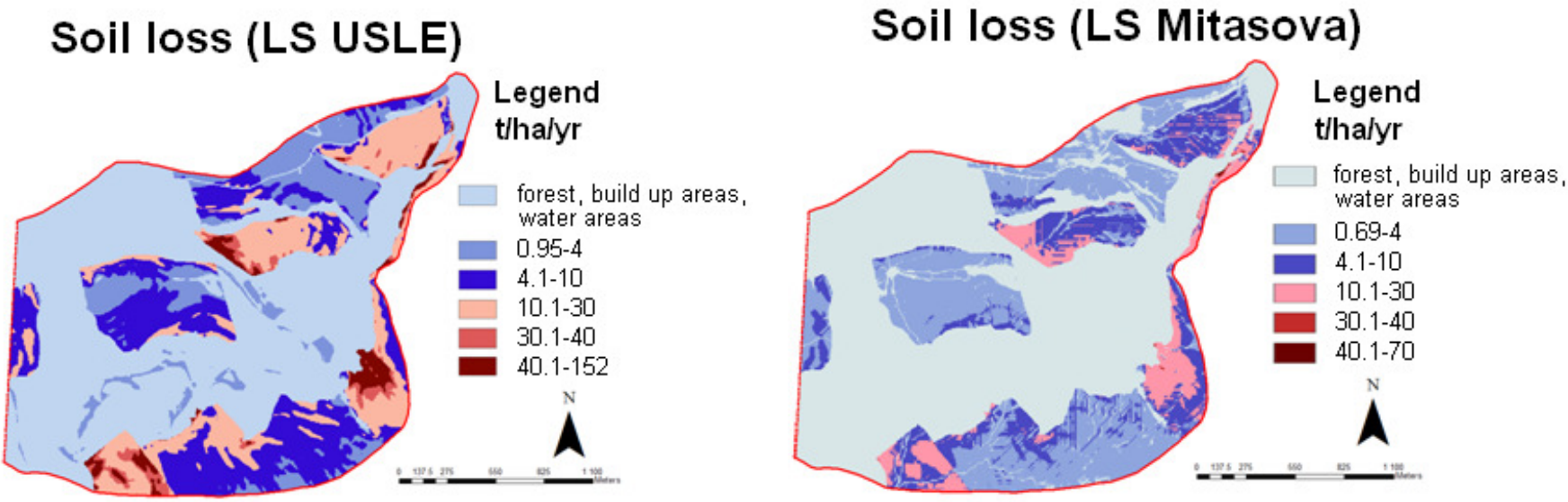

Fig. 6. Soil loss layer using different calculations of LS factors

\section{Conclusion}

Design and development of appropriate erosion control measures is connected with knowledge about the incidence and symptoms of water erosion in landscape. Soil loss calculation in the catchment is laborious and time-consuming, but using GIS we can identify areas threatened by water erosion. The most difficult phase of calculation in GIS is to create individual layers, because they are not yet available areally.

In this paper the possibilities of calculating the soil loss through water erosion in GIS environment using empirical model USLE were shown. The calculation was focused on the use of variant topographical factors. The resulting values of soil loss were compared according to the methods of calculating the LS factor, which was seen as a change in topographic factor affecting the value of soil loss.

The advantage of the calculation in GIS environment is the possibility of determining the total soil loss from the whole plot, as well as from each network element and thus suggest erosion control measures only in those parts of the land that are truly at risk. While manual calculation allows the determination of soil loss only from the land as a whole.

\section{Acknowledgements}

The authors are grateful to the Slovak Grant Agency for Science (Grant No. 1/0882/11) for financial support of this work.

\section{References}

[1] European environment agency. 2003. Assessment and reporting on soil erosion. Background and workshop report. Technical report 94. Copenhagen. $103 \mathrm{pp}$.

[2] European commission. 2010. The state of soil in Europe. A contribution of the JRC to the European Environment Agency's Environment State and Outlook Report - SOER 2010. Luxembourg. 76 pp

[3] Slovak environental agency [online]. 2013. Soil erosion (in Slovak). Bratislava [cited 15 December 2013]. Available from Internet: http://www1.enviroportal.sk/indikatory/detail.php?id indikator=496.

[4] Wischmeier, W. H.; Smith, D. D. 1978. Predicting Rainfall Erosion Losses. A Guide to Conservation Planning. Agriculture Handbook No. 537. Washington D.C.: U.S. Department of Agriculture. $58 \mathrm{pp}$.

[5] Mitasova, H.; Mitas, L.; Brown, W. M.; Johnston, D. 1996. Multidimensional Soil Erosion/deposition Modeling. PART III: Process based erosion simulation. Report for USA CERL. USA: University of Illinois. $28 \mathrm{pp}$.

[6] Garcia Rodriguez, J.; Gimenez Suarez, M. 2010. Historical review of topographical factor LS of water erosion models, Aqua-LAC 2(2): 56-61.

[7] Wilson, J. P. 1986. Estimating the topographic factor in the universal soil loss equation for watersheds, Journal of Soil and Water Conservation 41(3): $179-184$.

[8] Sinha, D.; Joshi, V. U. 2012. Application of Universal Soil Loss Equation (USLE) to recently reclaimed Badlands along the Adula and Mahalungi Rivers, Pravara Basin,Maharashtra, Journal Geological Society of India 3(80): 341-350. http://dx.doi.org/10.1007/s12594-012-0152-6

[9] Malisek, A. 1990. Evaluation of the rainfall and runoff factor by geographic location (in Slovak), Geografický časopis 42: 410-422.

[10] Simms, A. D.; Woodroffe, C. D.; Jones, B. G. 2003. Application of RUSLE for erosion management in a coastal catchment, southern NSW, in Proc. of MODSIM 2003: International Congress on Modelling and Simulation, vol. 2, Integrative Modelling of Biophysical, Social and Economic Systems for Resource Managment Solutions, 2003. Townsville, Queensland, 678-683.

[11] Ministry of Environment of the Slovak Republic. 2004. Act No. 220/2004 Coll. On Protection and Exploitation of Agricultural Land and Amending and Supplementing of Act No. 245/2003 Coll. on Integrated Prevention and Control of Pollution of the Environment and Amending and Supplementing of Certain Acts (in Slovak). 